\title{
El castillo de Brihuega y sus orígenes islámicos
}

\author{
M. a Magdalena Merlos Romero *
}

\section{RESUMEN ABSTRACT}

El castillo de los Arzobispos de

Toledo en Brihuega remonta sus origenes al periodo de dominio islámico. La hipotética reconstrucción del sistema defensivo originario se basa en el análisis de su emplazamiento, materiales y técnicas constructivas empleados, planta y alzado. La datación del conjunto se fundamenta en paralelos establecidos con estructuras similares de la época emiral y califal, en el ámbito geográfico de la Marca Media.
The castle of Brihuega has its origin from the Muslin domination time. The hypothetical rebuilding of the original defensive systeme is based on his situation, materials and architeric techniques used, ground-plan and elevation. The castle date is settled by pararelisms with similar structures from the emiral and califal periods, within the geographic zone of the Marca Media.

El protagonismo de Brihuega en la Edad Media viene fundamentalmente determinado por su papel en el señorío territorial del arzobispo de Toledo. Pero el proceso arquitectónico y urbano de Brihuega llevado a cabo por los arzobispos, se establece sobre la base de conceptos y transformaciones ya gestadas por el monarca taifa toledano Al-Mamún y por Alfonso $\mathrm{VI}$ sobre unas estructuras preexistentes.

Desde las primeras fechas de la llegada del Islam a la Península, Brihuega debió ser un pequeño núcleo militar. Esta función castrense, que posiblemente tenga su origen en el periodo del emirato, vendría definido por su emplazamiento en la Marca Media. En línea con Alcalá, Sigüenza,

* Tercer Ciclo. Departamento de Historia del Arte. UNED. 
Canales, Atienza o Medinaceli, constituía una plaza destacada, aunque no tan relevante como éstas, puesto que las fuentes islámicas no la citan. Tras la caída del Califato, toda la zona alcarreña pasaría a integrarse en la taifa toledana, una vez consolidada la frontera bajo Al-Mamún. Hecho que acontece a raíz de la paz firmada con la taifa de Zaragoza, en la que participa activamente Fernando I, en torno a los años 1040-1050.

Tal vez en Brihuega se recuperase un asentamiento existente con anterioridad al dominio hispanomusulmán, de época romana o visigoda ${ }^{1}$. Un pequeño hábitat rural podría haber constituido el origen de Brihuega, formado en una zona de gran fertilidad, inserto en ese esquema característico de la cultura islámica que sería la diseminación de estos núcleos o alquerias por todo el territorio.

El denominador común de los textos conocidos sobre Brihuega es su carácter de enclave escogido desde época islámica, sustentado en la bondad del lugar y en su excepcional entorno natural. Sólo en este contexto se comprende la conformación de un conjunto arquitectónico en origen defensivo, al que con posterioridad se aúnan unas funciones residenciales y de recreo, donde paisaje y arquitectura se entremezclan deliberadamente.

Las fuentes en cualquier caso abundan en la preexistencia de una estructura fortificada en el momento de la toma de posesión del lugar por parte de Alfonso VI.

Al margen de las relaciones etimológicas que B. Pavón Maldonado establece entre el término bury y el nombre de Brihuega, ya en el siglo XIII se consideraba el origen islámico de la función defensiva del lugar. La Crónica de España de Alfonso X señala la existencia de un buen castiello contra Toledo. Rada por su parte explica cómo Alfonso VI recibe de manos de Al-Mamún un logar vicioso (ameno) e de mucha caza e avia y (alli) buen castillo para contra Toledo ${ }^{2}$. Las fuentes bibliográficas en general confirmarán el origen islámico del castillo de Brihuega: no es Brihuega la

\footnotetext{
El Islam con independencia de los núcleos que crea de nueva planta, había tendido a ocupar asentamientos de origen visigodo, romano o prerromano.

R. XIMenius de Rada, De rebus hispaniae. Ed. Fac. Madrid, 1989, III, L. VI, cap. XVI. El relato es recogido también por Alfonso $X$ y, posteriormente, por la mayor parte de la historiografia, entre la que destacan las obras de F.J. RIVERA RECIO, La iglesia de Toledo en el siglo xil (1086-1208). Roma, 1966, Toledo 1983. vol I, pág. 25; B. PAvon MALDONADO, Guadalajara medieval. Arte y arqueología árabe y mudéjar. Madrid, 1984, pág. 161; L. TORRES BALBÁS, "La capilla del castillo de Brinuega y los edificios de D. Rodrigo Jiménez de Rada", A.E.A (1941), págs. 279; F. Layna SerRano, Castillos de Guadalajara. Guadalajara, Ed. 1994, pág. 255. Los hechos se datan en 1072, durante el periodo de nueve meses en que Alfonso VI es acogido por Al-Mamún en su corte, con el trasfondo de los conflictos hereditarios que suceden a la muerte de Fernando I, rey de Castilla y León.
} 


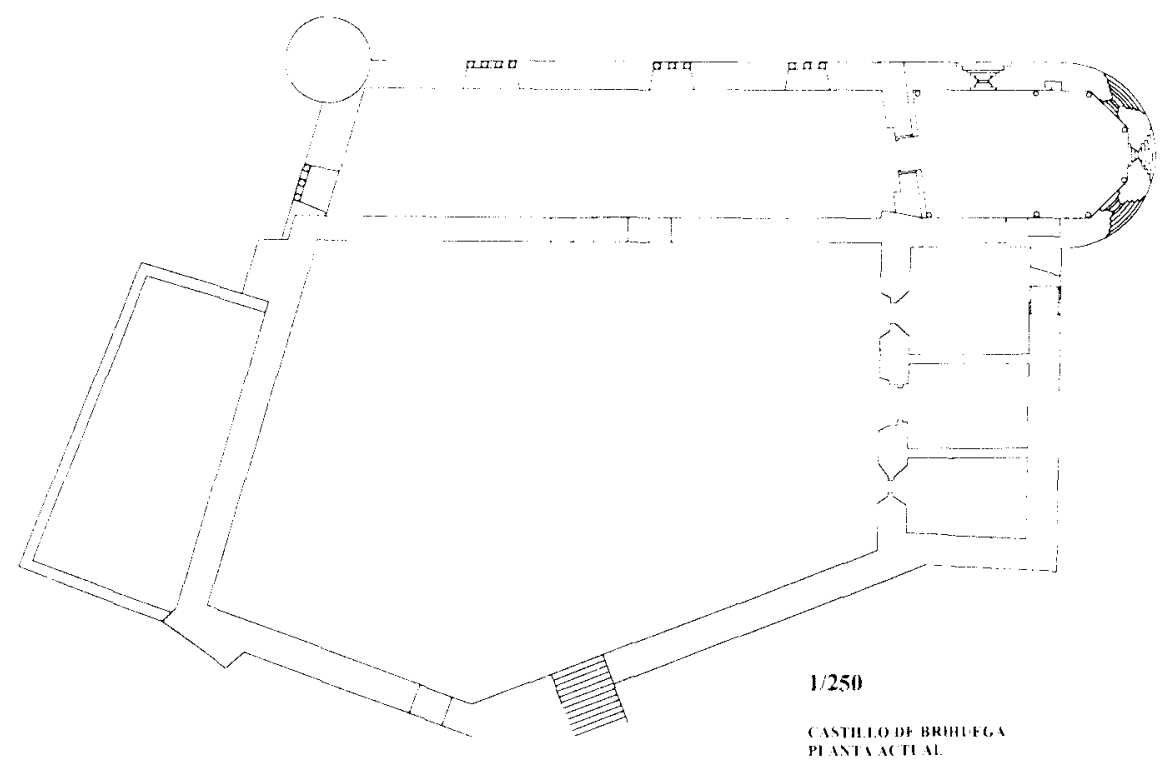

Fig. 1.

alquería que fundó Don Alonso, y que ya existía la villa de Brihuega, con su castillo y fortaleza ${ }^{3}$.

El valor militar originario del enclave se perpetuará durante el dominio cristiano, como demuestran los textos latinos de los siglos xII y principios del XIII, que designan a Brihuega como oppidum (bula de Celestino III de $1192{ }^{4}$ ) o castrum (bula de Inocencio III en $1210^{5}$ ).

El testimonio de Alfonso $X$ buen castiello contra Toledo destaca la crucialidad de Brihuega como punto esencial en la estrategia ofensiva sobre Toledo, que habrá de culminar con la toma de esta ciudad. Brihuega será un punto relevante en las campañas previas a la fecha de 1085, como integrante de una línea de ataque trazada por Uclés,

F. DE BEJAR, Historia de la milagrosa imagen de Nuestra Señora de la Peña, patrona de Brihuega. Madrid, 1733. Libro 2. ${ }^{\circ}$, pág. 53.

Archivo Capitular de Toledo (ACT) X.7.2.13.

J. Catalina Garcia, "La Alcarria en los dos primeros siglos de su reconquista", Discursos leidos ante la Real Academia de la Historia en la recepción pública de..., 1897. Reed. Guadalajara, 1973, pág. 79; F. FITA, «Bula de Inocencio IIl», BRAH, VIII (1886), págs. 400-401; ACT, LP fol. 92v. 93v. Oppida viene a significar ciudad, cabeza de un territorio, pero también plaza fuerte o recinto fortificado. Es la voz castrum la que el latín utiliza para referirse a un castillo, y la que, para el caso de Brihuega, termina de confirmar la presencia de defensas arquitectónicas. 


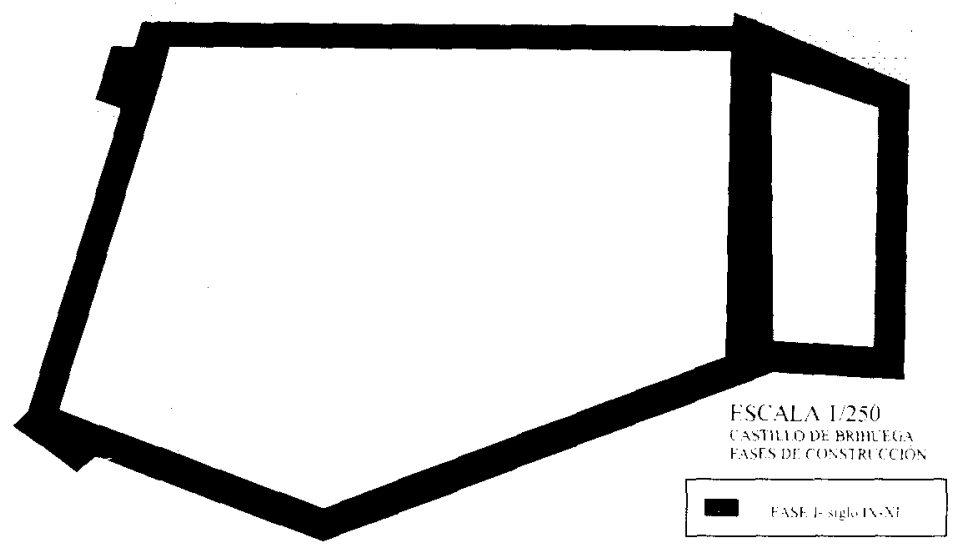

Fig. 2.

Huete, Zorita, Guadalajara, Jadraque y Atienza. Este papel desarrollado por Brihuega aporta visos de verosimilitud a la tradición recogida en el siglo XVI por el viajero Henry Cock, quien relata cómo el castillo fue reconstruido por Alfonso VI: dicen que éste fue reparado de Alfonso VI que ganó a Toledo ${ }^{6}$.

Sin embargo, y en cuanto a las fuentes islámicas se refiere, la omisión de Brihuega en las mismas ha llevado a parte de la historiografía a cuestionar su valor estratégico y la existencia de la fortaleza durante época musulmana.

No obstante, la bibliografía más reciente admitirá los orígenes islámicos del sistema defensivo. M. Retuerce subraya la importancia para el Islam del Castillo de Peña Bermeja. Sería en Brihuega donde los reyes toledanos poseerian alguna clase de edificio más o menos fortificado ${ }^{7}$, pero sin llegar a retrotraer sus origenes hasta las épocas más próximas a la invasión islámica de la Peninsula. A. Herrera Casado ${ }^{8}$ apunta como inequivocamente probado la existencia de un castillete o torreón defensivo árabe.

E. Cock, Relación del viaje hecho por Felipe II, en 1585 a Zaragoza, Barcelona y Valencia. Madrid, 1876. Ed. Fac. Valencia, 1995, pág. 17.

M. Retuerce, Guía de castillos de Castilla-La Mancha. Madrid, 1983, págs. 71-72.

A. Herrera Casado, Castillos y fortalezas de Castilla-La Mancha. Toledo, 1989, págs. 169-174. 
Más bien ha de pensarse que, a pesar de que el valor militar se perpetúa con el dominio islámico, el destino castrense originario de Brihuega pierde protagonismo, coincidiendo con el momento en que queda consolidada la línea fronteriza entre Toledo y Zaragoza, tras los movimientos de límites producidos durante la Fitna, caída del Califato e inicio del periodo de los reinos de Taifas ${ }^{9}$.

Desde luego el sistema fortificado originario sufriría múltiples modificaciones en su fisonomía, aunque orientadas al mantenimiento de las estructuras defensivas y a su adaptación a una función añadida, la residencial, propiciada a partir del periodo taifa. En cualquier caso, estas reformas se sucederían tanto en el periodo de dominio islámico como cristiano, aunque las noticias sobre intervenciones arquitectónicas arrancan de la época de Alfonso VI, si se consideran las afirmaciones de Cock. F. de Béjar apunta estas reformas en las defensas, pero de modo genérico en estas ocasiones [hacia 1084] siéndole preciso fortificar las murallas de Brihuega... ${ }^{10}$. Algunos investigadores desestiman estas iniciativas con base en la oscilación de la línea de frontera y el corto periodo de tiempo en que Alfonso VI poseyó el enclave $(1071-1086)$ ". Precisamente esta inestabilidad y el papel que Brihuega desempeñó en la toma de Toledo, permitirian en tal caso justificar ciertas reformas.

Así, desde un punto de vista militar, y a la luz de las fuentes escritas, la evolución arquitectónica del castillo viene definida por la adecuación de un recinto castrense a una nueva función, la residencial, sin menoscabo de las funciones defensivas.

Con este trasfondo histórico, es fundamental preguntar por la auténtica pervivencia de los conceptos y formas islámicas en el castillo de Brihuega, y definir ese primer núcleo fortificado que a la postre los arzobispos adoptarán como residencia. El análisis pormenorizado de sus elementos ha permitido establecer varias secuencias constructivas. Estas fases contribuyen en última instancia al establecimiento de una periodización cronológica para el castillo, con su punto de partida en la etapa de dominio islámico.

Ello determina que el estudio de los dispositivos militares del castillo haya de buscarse en el conocimiento del sistema defensivo originario, verdadero punto de partida de una arquitectura de historia harto compleja.

IBn Al-Kardabus, Historia de Al-Andalus. Ed. F. Maillo Salgado. Madrid, 1993

F. DE Bejar, Op. cit., pág. 148.

A. M. MORENO ATANCE, "El protogótico en Brihuega", Wad al Hayara, 9(1982), pág. 220. 
El castillo original islámico se emplazó sobre un lugar de indiscutible valor estratégico, una peña que domina el valle del Tajuña. Al Este está limitado por un barranco, desdibujado cauce de un arroyo que baja al Tajuña desde el norte, atravesando la villa y hoy oculto por ésta. Este aprovechamiento de los recursos naturales no es sólo defensivo. La orientación al Sur del castillo propiciaría en igual medida el asentamiento humano al amparo del mismo y en la bajada hacia el valle, proporcionando un resguardo adicional a la población, frente a una dura climatología.

El núcleo original del castillo está conformado por un recinto casi cuadrangular. Tendente a la regularidad, está muy determinado por la orografía, puesto que se ciñe a la cota más elevada de la peña, aprovechándose como defensa natural el corte con que por el sur mira al valle.

Los lienzos y torres correspondientes al trazado del primitivo castillo han podido ser detectados por compartir unos rasgos comunes en cuanto a materiales y técnicas constructivas se refiere, que a su vez los diferencian de otros elementos constructivos del conjunto militar de Brihuega.

El asiento del castillo original se produce directamente sobre la roca viva, sin ningún tipo de superficie de transición. Este sistema supone economía en las obras de cimentación. Se detecta en el paramento del

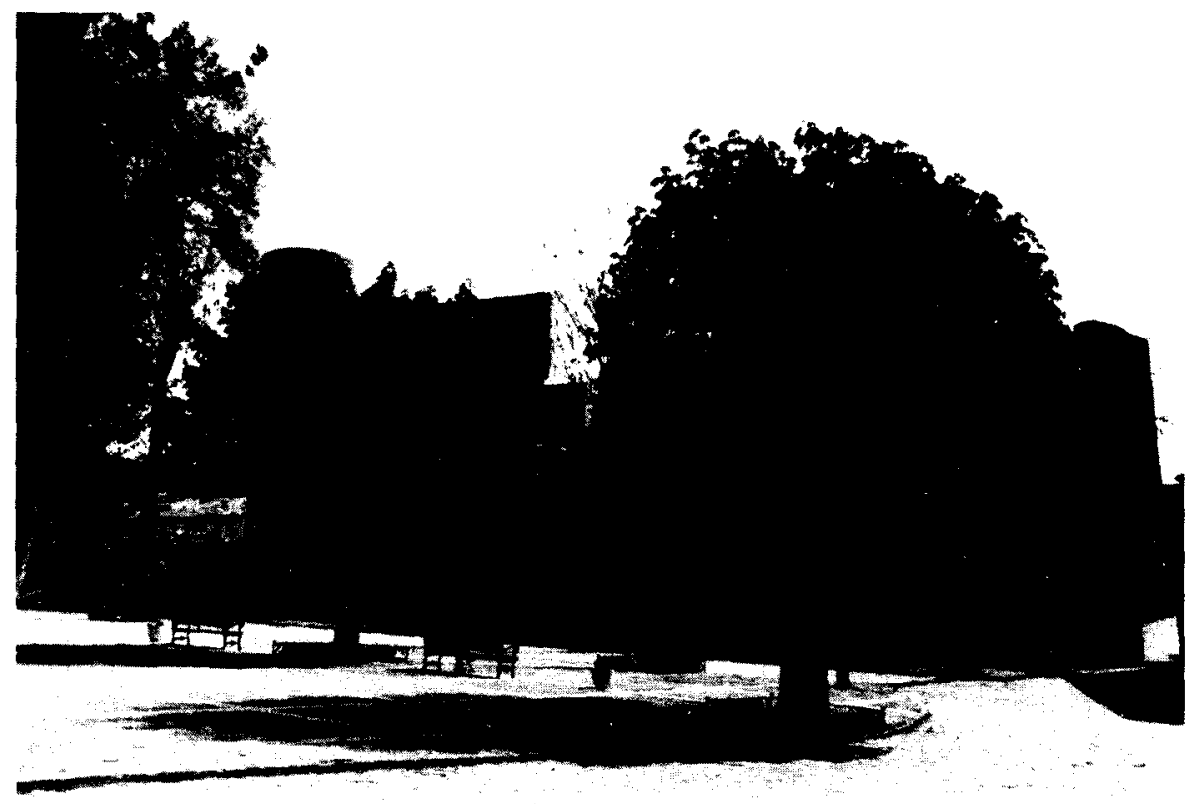

Fig. 3. Lienzo Oeste del castillo. 
paralelepípedo que limita el núcleo del castillo al Este y Sureste [il. 4, 5], y en dos torres de escasa envergadura situadas en el ángulo Suroeste [il. 6] y en el flanco Oeste [il. 7]. La base se aprovecha totalmente, generando unos paramentos que proyectan hacia arriba la vertical de la roca. El empleo de la piedra de la zona contribuye a esta indiferenciación entre plataforma pétrea y arquitectura.

Los muros son de considerable grosor, en torno a los dos metros. El sillar se reserva para las aristas, mejor o peor escuadrado. Así se perfilan las torres y el paralelepípedo citados.

El sillarejo se organiza conformando una pared externa, que se corresponde con otra paralela más interna y oculta. Entre estas dos caras de mampuesto se dispone un relleno de yeso. Esta técnica se puede observar en los vestigios de un muro empotrado en el ángulo Sureste de la Sala Norte del castillo, en un punto limitrofe con la torre del homenaje [il. 1, 2, 8].

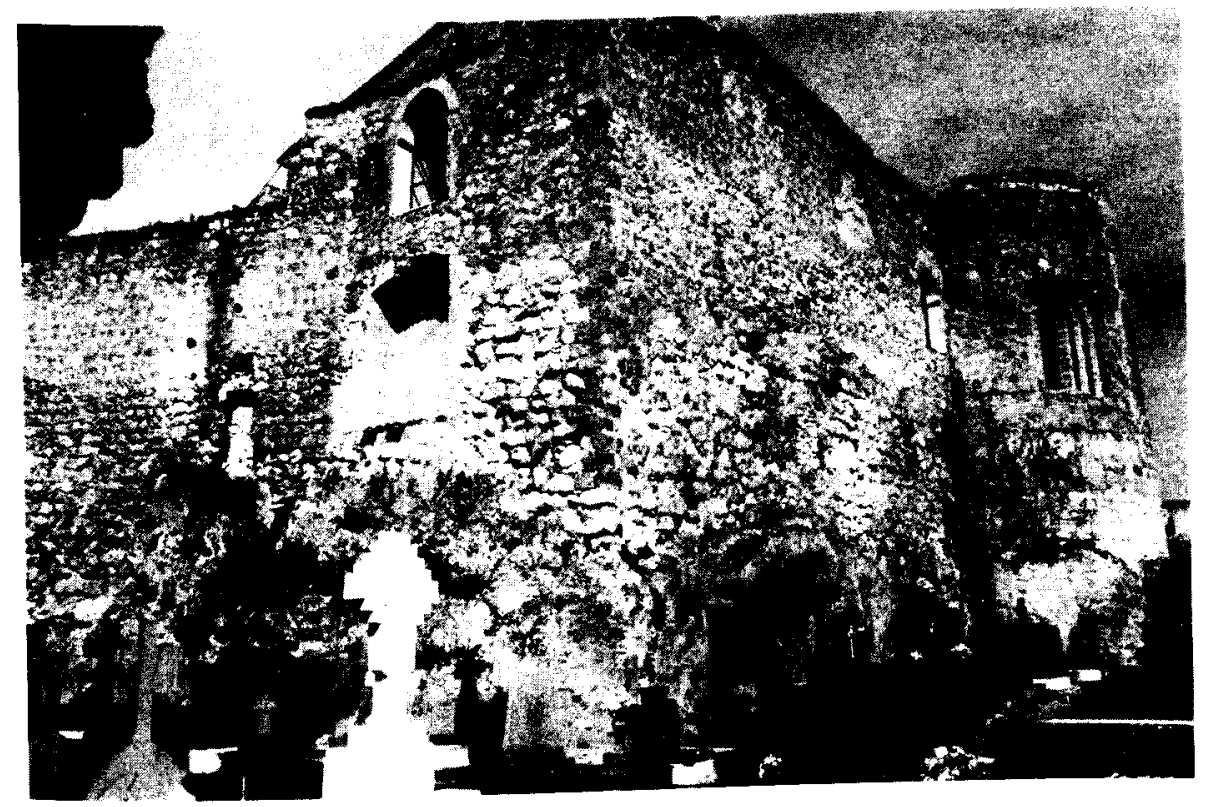

Fig. 4. El castillo desde el Sureste. La torre Este.

Este muro debió corresponder al trazado primitivo del castillo, por cuanto comparte con los puntos descritos de la fortaleza, un aparejo exterior de idénticas características. Esta factura está definida por el empleo de un sillarejo poco trabajado, de dimensiones regulares. Conforma hiladas de acusada horizontalidad, derivadas del propio sistema constructivo, que obliga a 
subir el muro interior y exterior simultáneamente, para favorecer su relleno. El sillarejo está dispuesto a soga, técnica que contrasta en algunos puntos con la ocasional presencia de piezas dispuestas a modo de sardinel. El carácter tosco de éste permite interpretarlo como una versión dudosamente refinada de la técnica constructiva a tizón. Esta organización de los materiales es de escaso valor tectónico, por cuanto las piezas nunca abarcan el grosor del muro, que se conformaba mediante la erección de dos muros paralelos. Su empleo desde luego es muy limitado, algunas hiladas en la zona inferior de las torres SO y O [ii. 6, 7]. Por ello cabe pensar que su función sería la de nivelar los materiales y favorecer la erección de los muros, a partir de la base irregular que proporciona la roca de asiento.

Todos los caracteres técnicos y materiales descritos están perfectamente documentados en otras construcciones militares. Sin embargo, el más peculiar, por cuanto permite avanzar una adscripción tanto tipológica como cronológica, es el de la disposición de aparejo a sardinel.

Para algún autor ${ }^{12}$ este pseudo-tizón constata el origen árabe del castillo. Sin embargo la presencia de hiladas semejantes en un grupo muy determinado de construcciones, avalarán más bien una adscripción beréber.

La disposición de hiladas a sardinel aparece conjuntamente con la técnica de levantamiento de muros paralelos, encaminada a homogeneizar la irregularidad de materiales, en la arquitectura militar beréber que define la Marca Media. Algunas muestras se encuentran en la zona de Talavera (Castros) ${ }^{13}$, aunque las más interesantes son las correspondientes a ámbitos más cercanos a Brihuega. De este grupo destacan los paramentos islámicos de la alcazaba de Cuenca ${ }^{14}$, la Torre del Andador de Albarracín (Teruel), y la de Los Casares en Riba de Saelices (Guadalajara). También ha sido localizado este tipo de técnica en una de las torres del castillo de Zorita de los Canes, y en puntos de Alcalá la Vieja.

Se han interpretado como imitación en el ámbito rural de los aparejos califales áulicos ${ }^{15}$, aunque S. Martínez Lillo encuentra un referente norteafrica-

12 B. PAVON MALDONADO, op. cit., pág. 163-164.

13 S. MARTínez LILlO, "Arquitectura militar de ámbito rural de la Marca Media (al-taggr al-awsát). El alfoz de Talabira. Antecedentes y evolución", Boletín de Arqueologia Medieval, 4 (1990), págs. 135-173.

14 A. Almagro Gorbea, "El sistema defensivo de Albarracin", "l Congreso de Arqueología Medieval, Madrid, 1987, t. II, págs. 71-84, y del mismo autor «Las torres beréberes de la Marca Media. Aportaciones a su estudio", Cuadernos de la A/hambra, 12(1976), págs. 279-305; y "Restos musulmanes en las murallas de Cuenca", Cuadernos de la Alhambra, 15-17 (1979-1981), págs. 233-248.

15 Cfr. S. Martinez Lillo, op. cit., pág. 151; A. Almagro Gorbea, «Restos...", págs. 239, 246. 
no más cercano a la Península al Sur de Túnez, el asentamiento fortificado de Qsar Qadîm. En última instancia, remiten a una técnica de escasa eficacia tectónica, conocida en la primera arquitectura del Islam, en los castillos del desierto de Siria y Jordania (Qusayr Amhra, Harrana). De esta manera se deduce que el modelo llegaría de Oriente a través del Norte de África siguiendo las líneas de penetración en la Península de la propia invasión musulmana. Su difusión en la versión que se localiza en Brihuega, se circunscribiría al Medio y Alto Tajo, en la Marca Media, a donde llegaría de la mano de grupos beréberes que se asientan en esta zona entre los siglos $\mid x$ y $\mathrm{X} \mid$.

Esta adscripción tipológica, geográfica y cronológica alcanza a otros rasgos formales. El asentamiento directo sobre la roca sin cimientos es una técnica, junto con el empleo de la roca del lugar, que se observa en conjuntos defensivos de la Marca Media como Castros. El grosor de los muros, entre 1,5 y $2 \mathrm{~m}$. también coincide con el adoptado en las construcciones de El Andador (1,6 m.), Los Casares o Cuenca (entre 1,6 y 1,9 m.).

La disposición de los materiales, definida por el empleo del sillarejo en toda la superficie de los muros y la reserva del sillar para las aristas, mejor o peor escuadrado, es otra característica común de todos estos ejemplos. Aunque la técnica se conocerá en fases posteriores medievales de la arquitectura militar, es interesante constatar cómo ya existe en este tipo de arquitectura de una zona muy concreta y próxima a Brihuega y en una cronología (entre fines del $X$ y el $X I$ ) que sirve de pauta para una datación del núcleo originario del castillo de Brihuega.

La localización de estos caracteres técnicos y materiales descritos en puntos muy determinados del conjunto defensivo, así como la elocuente ausencia de los mismos en otras zonas, permiten la reconstrucción de la planta del castillo de Brihuega en su trazado inicial. El sistema defensivo de Brihuega responde a la disposición de dos elementos interrelacionados, la torre y el recinto defensivo complementario [il. 1,2].

La torre ha sufrido profundas modificaciones, que dificultan su identificación y estudio. En la actualidad constituye la crujía Este del castillo. Su planta es rectangular, de 20,6 m. por 10,5 m., con los lados mayores orientados de Norte a Sur. Sus laterales Este y Sur permanecen exentos [il. 4, 5]. Su cierre Norte quedó oculto por la torre del homenaje, añadida en época cristiana [il. 9]. Del mismo sólo es visible el ángulo Noroeste, el vestigio de muro a que se hacía referencia, identificado al interior de la crujía Norte del castillo [il. 8]. El trazado del paramento Oeste coincidiría con la línea que actualmente limita con el patio. De este modo, la torre estaría exenta en sus orígenes por todos sus laterales, excepto por este muro a poniente, dispuesto hacia el interior del recinto anexo. 


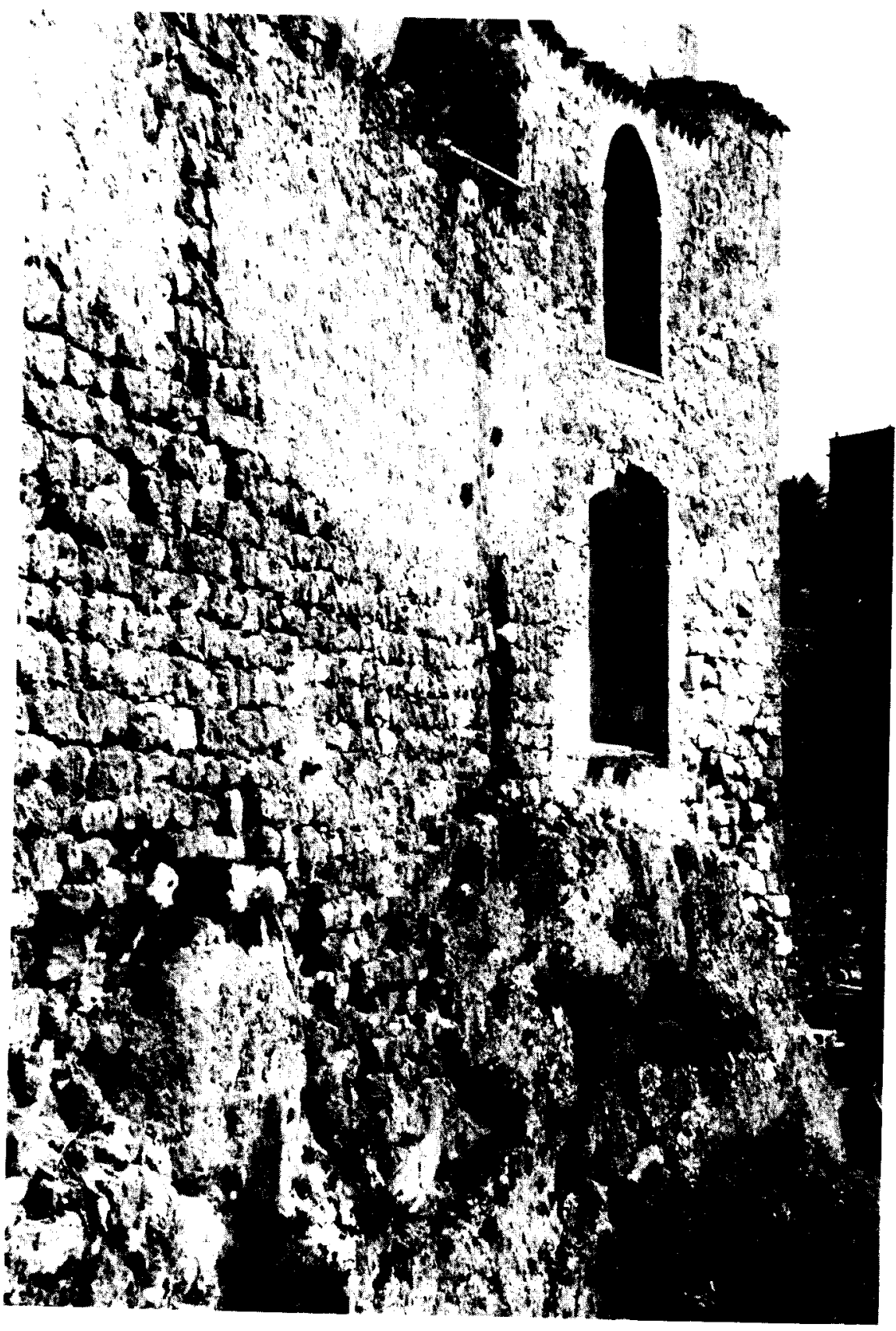

Fig. 5. Lienzo Sur del recinto originario. 
El perímetro del recinto originario vendría a coincidir con el del patio central del castillo ${ }^{16}$ [il. 1, 2]. De este modo arrancaría del ángulo Noroeste de la torre primitiva, perteneciendo a su trazado la pared que separa el patio de la crujía Norte del castillo, así como el muro Oeste, al cual se adosa en un nivel inferior una estancia de época tardía. EI lienzo sur originario coincide con el muro por el que hoy se accede al patio. Asi el recinto se cerraría por el ángulo SO de la torre. La planta actual del castillo delata este punto de unión, con un cambio de dirección del flanco sur del castillo, perfectamente ceñido a la roca sobre la que asienta. Esta adaptación a la orografía es la que determina que esta panda sur presente otro quiebro. El modo de llevarlo a cabo explica por qué los lienzos del núcleo original y las torres surgen sobre los canchales, asentados sobre ellos directamente sin establecer cimentación alguna.

Las dimensiones de este recinto quedarian establecidas en 29 por 40,5 $\mathrm{m}$. aproximadamente, simplificando su forma. La pretendida regularidad hubo de compaginarse con una deliberada intención por hacer coincidir su planta con la cota más elevada de la plataforma sobre el Tajuña.

Este hipotético trazado está avalado por la presencia de unos vestigios que hoy pasan prácticamente desapercibidos, desdibujados en el conjunto del castillo. Son dos torres sin volumen acusado hacia el interior del recinto, y de escasa proyección al exterior. Presentan dimensiones similares. La torre Suroeste [il. 6], con un ancho de 4,3 m. y una proyección de $1,42 \mathrm{~m}$.; la Noreste [il. 7], de $3,25 \mathrm{~m}$. de ancho y 1,33 m. de proyección. La disposición de las mismas, la primera en el lienzo Oeste, próxima al ángulo Noroeste, la segunda en el ángulo Suroeste, confirma su función de elementos de refuerzo.

Es interesante argumentar cómo la torre Noroeste y el muro que limita el patio con la crujía Norte fueron puntos externos del recinto originario. La crujía Norte se revela como un cuerpo adosado a una estructura previa. Prueba de ello es la perfecta coincidencia entre la superficie de la roca donde asienta la citada torre y la planta de ésta [il. 7]. De tal manera el muro correspondiente a la panda Norte, dispuesto hacia el Oeste, y a continuación de la torre en su lateral izquierdo, linda con la roca a un nivel inferior, pero ya no se sustenta en ésta, sino en un suelo que evidencia una colmatación del terreno ex profeso y a posteriori. Por ello se explica la doble altura de este volumen, que contrasta con la planta única, sorbe la 


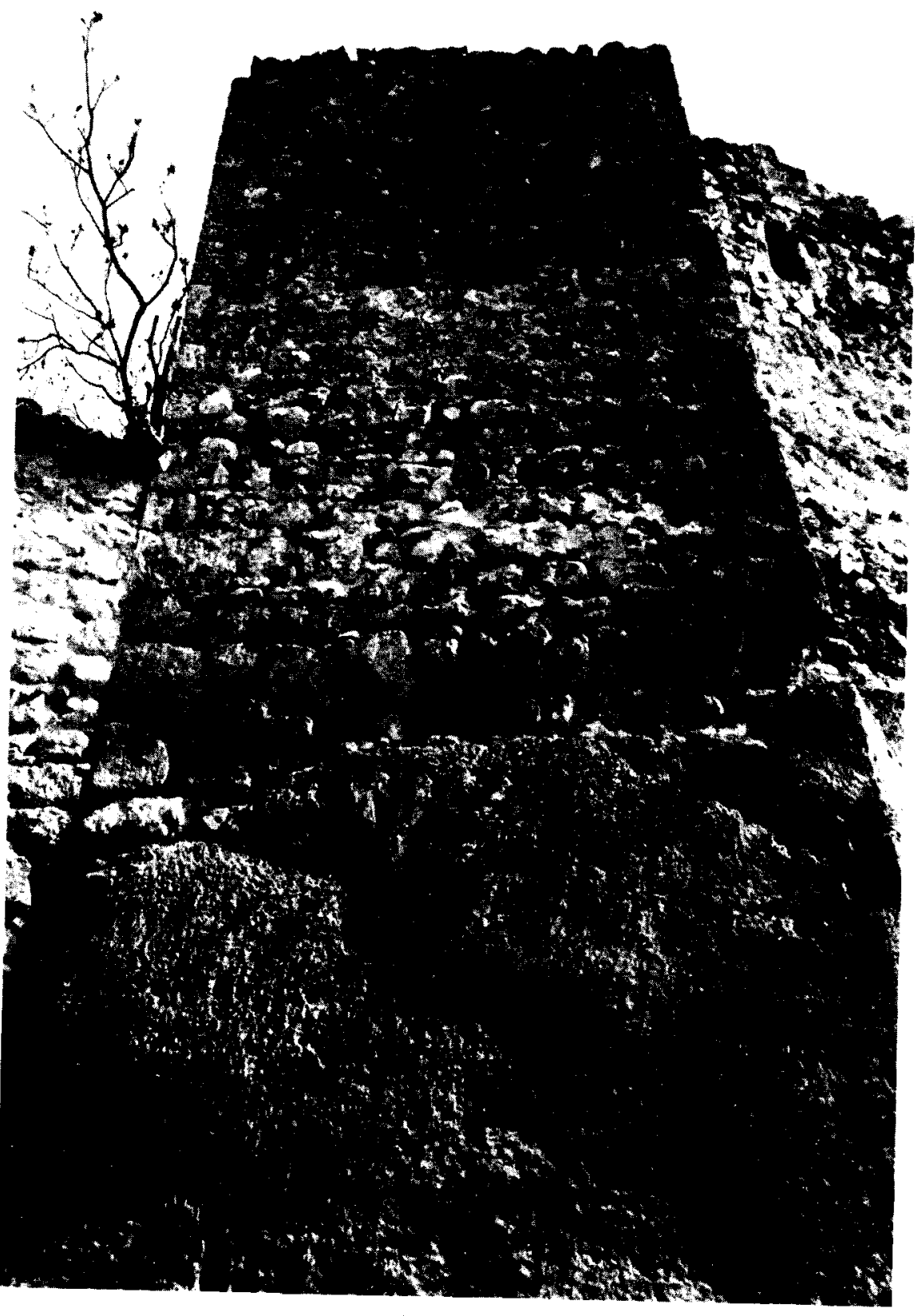

Fig. 6. Torre Suroeste. 


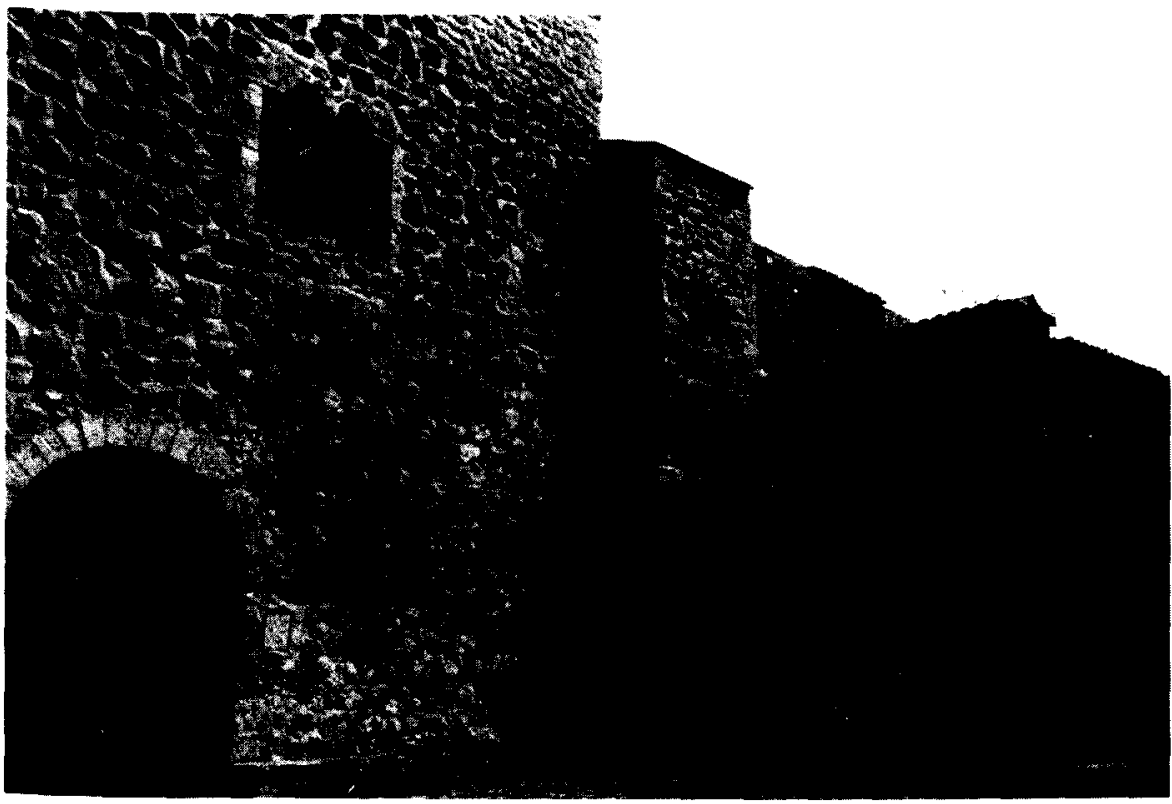

Fig. 7. Lienzo Oeste. En el centro la torre originaria. A la izda. la crujia Norte.

plataforma de la roca y a un nivel superior del recinto original, o lo que es lo mismo, del perímetro del patio alto actual.

En cuanto al muro que separa la zona norte del núcleo primitivo, destaca su grosor $(1,8 \mathrm{~m}$.). El dato permite su identificación con el paramento exterior de un recinto al que se adosaria por el Norte una estructura levantada con posterioridad [il. 10]. A ello se suma el hecho de que un ángulo de la torre del recinto primitivo penetre y quede asimilado en la misma. Por último, los propios caracteres formales y estilísticos de esta crujía ${ }^{17}$, avalan su identificación con fases posteriores de la compleja evolución constructiva del castillo. Son ampliaciones encaminadas a conferir una función residencial a una arquitectura concebida únicamente con fines militares.

De esta manera queda perfilada la planta del sistema defensivo primitivo. Estaría integrada por una torre como elemento principal y destacado. Su complemento sería un modesto recinto, cuyos ángulos, los puntos más

Por otra parte, la capilla y el volumen de la torre del homenaje dispuesta al Este de la crujía, se revelan como posterior a ésta. Sobre este particular L. TORRES BALBAS, "La capilla del castillo de Brihuega y los edificios de D. Rodrigo Jiménez de Rada", A.E.A (1941) pág. 284. 


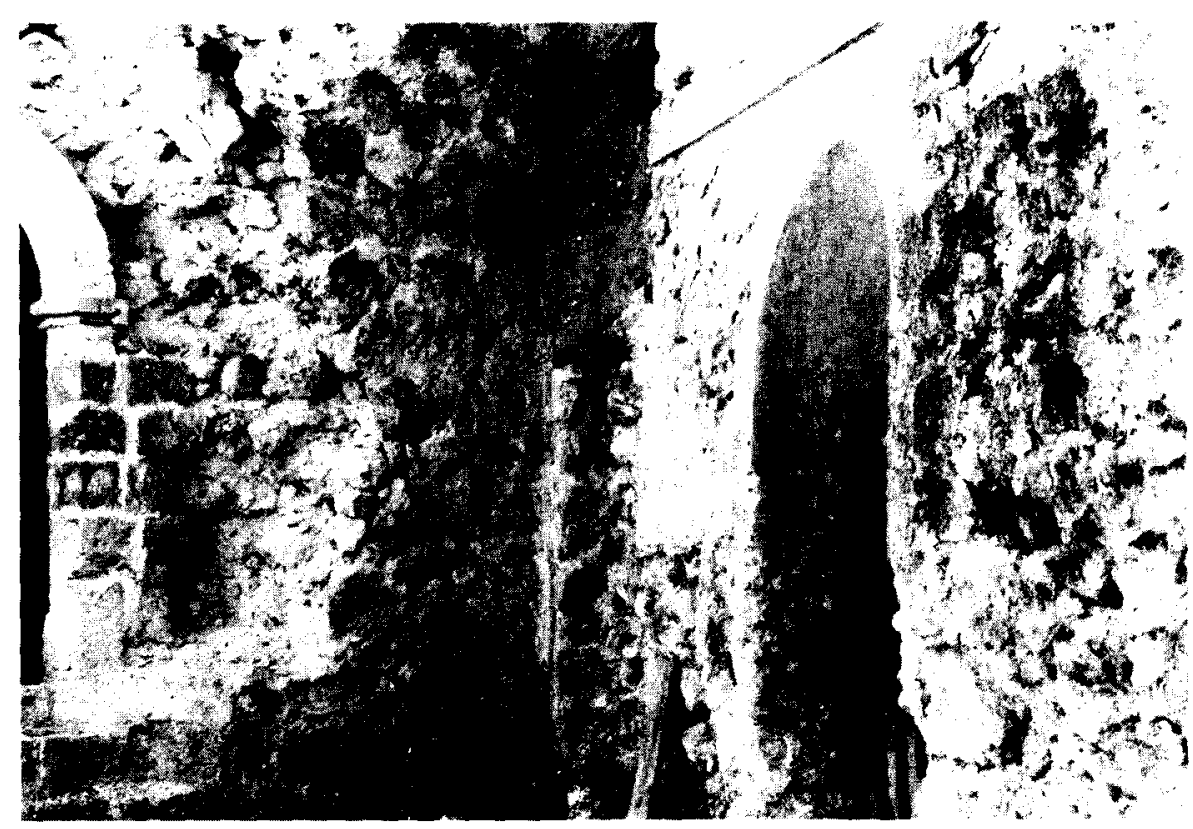

Fig. 8. Ángulo de encuentro de la torre del Homenaje (izqda.) con el recinto original.

vulnerables, estarian reforzados por sendas torres de escasa proyección al exterior.

Los elementos que integran este sistema están documentados en la arquitectura hispanomusulmana. El trazado de un recinto reforzado por torres macizas de escasa proyección es característico de las construcciones militares emirales y califales. Las propias dimensiones de las torres remiten a las de Huesca, Madrid, Mérida, Talavera o Madinat Al-Zahra ${ }^{18}$, cuyo ancho se sitúa alrededor de los $4,5 \mathrm{~m}$. La coincidencia tipológica se acentúa respecto de las construcciones de la Marca Media y la Cuenca del Tajo con las que ya se establecian similitudes técnicas y materiales. La modesta proyección de las torres hacia el exterior es patente en las estructura defensiva de Castros, así como en las partes más antiguas de las de Cuenca y Zorita.

La disposición de estas torres en los ángulos asimismo evoca las edificaciones militares del Islam peninsular, hasta el fin del Califato, regulares,

" C. Escó SAmperiz, P. SencA, "La muralla islámica de Huesca", /I Congreso de Arqueología Medieval, Madrid, 1987, t. Il, págs. 589-601. 
con torres distribuidas en esquinas y centro de los lados, cuyo origen tal vez haya de buscarse en la arquitectura defensiva del primer Islam y en la tradición romana. En cualquier caso, la construcción briocense no dejaría de ser una ejemplificación muy esquematizada del modelo.

El otro elemento del conjunto militar de Brihuega, la torre, remite en igual medida, y de forma genérica, a la arquitectura hispanomusulmana desarrollada hasta el siglo $x$. Presenta no obstante otros distintivos, como la compartimentación interna de una de sus estancias (la que coincide con el nivel del patio del castillo), adscribibles al periodo cristiano. Ello ha propiciado lecturas erróneas ${ }^{19}$, que han impedido la identificación de la misma como construcción islámica.

La planta rectangular de la torre está presente en la arquitectura defensiva beréber del Alto Tajo -Albarracín, Tramacastilla, Los Casares-.

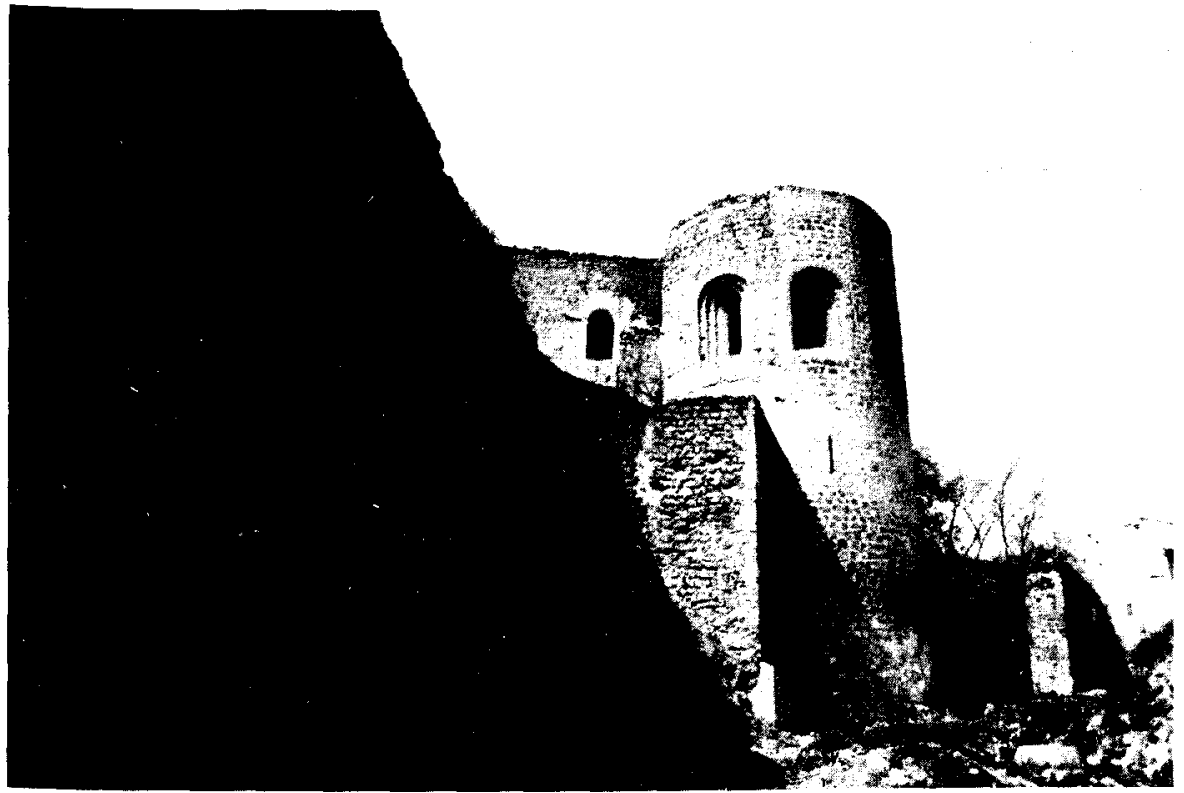

Fig. 9. La Torre del Homenaje desde el Noreste.

En las apreciaciones sobre la estaricia han de dejarse a un lado las evidentes modificaciones neogóticas del siglo xix. En cualquier caso, autores como $C$. ROMÁN PASTOR, "Historia y arquitectura medieval de Brihuega", Actas del Primer Curso de Brihuega: instituciones, arte y cultura. Brihuega, 1995, pág. 43, entienden la estancia tripartita como perteneciente a la primitiva construcción, aunque datan ésta en la segunda mitad del XII. La existencia del volumen de la sala se constata desde los orígenes arquitectónicos del castillo, pero éstos han de situarse no tanto en el periodo arzobispal, según afirma la autora, como en el periodo islámico. 
Las semejanzas son mayores respecto de la torre del recinto defensivo de Cuenca, con la que coincide en orientación y dimensiones ${ }^{20}$.

Estos ejemplos se han datado en fechas anteriores al siglo $\mathrm{XI}^{21}$. El modelo, identificado incluso en la arquitectura cristiana (Covarrubias), responde a un tipo plenamente difundido en el siglo $x$ en las Marcas, destacando principalmente en las construcciones militares de la Marca Media.

El conjunto defensivo que así queda establecido en Brihuega, de torre complementada con recinto, enraíza con la evolución tipológica de las construcciones del Alto Tajo en los siglos de dominio islámico, entre el $\mathrm{x}$ y el $\mathrm{x}$. El modelo tendría su punto de partida en la versión más sencilla de este tipo de fortificaciones, caracterizadas por la presencia de la torre como elemento único (Los Casares, Tramacastilla). En un estadio más avanzado se encontraria Brihuega, respondiendo a un sistema más complejo, integrado por un recinto, donde la torre es el elemento principal. Este segundo modelo es el conocido en Molina, Albarracín, Calatayud y Cuenca. Con ésta última ciudad compartirá incluso la distribución de torres de escasa proyección flanqueando el recinto amurallado.

La restitución del alzado originario del castillo es tarea ardua. Por una parte, algunas zonas del recinto están ocultas y modificadas por añadidos. Por otra, el paso del tiempo causa la pérdida de las alturas primeras de la construcción. Pese a su mutilación, las torres Suroeste y Noroeste y el lienzo Oeste evidencian una altura semejante que confirma su contemporaneidad [il. 3]. Este detalle facilita la restitución de un alzado de idéntica altura para la totalidad del recinto, excepción hecha de la torre Este, que como elemento principal del conjunto alcanzaría una elevación mayor, aún hoy manifiesta.

Es el alzado el que muestra las diferencias cronológicas entre el núcleo y la crujía Norte del castillo, apreciables por el contraste de la forma y el tamaño de los materiales del muro Oeste.

También corrobora los distintos momentos constructivos de la torre Este (islámica) y la torre del Homenaje (cristiana), por el empleo de técnicas diferentes (el ángulo NE en sillar de la torre queda incorporado en el paramento Este del castillo) [il. 9]. Es especialmente significativo comprobar cómo los muros exteriores primitivos de la torre islámica no

La torre de Cuenca mide $16 \mathrm{~m} \times 7,5 \mathrm{~m}$. La dimensión mayor discurre de Norte a Sur.

A. Almagro Gorbea, “Las torres..."; pág. 304. 


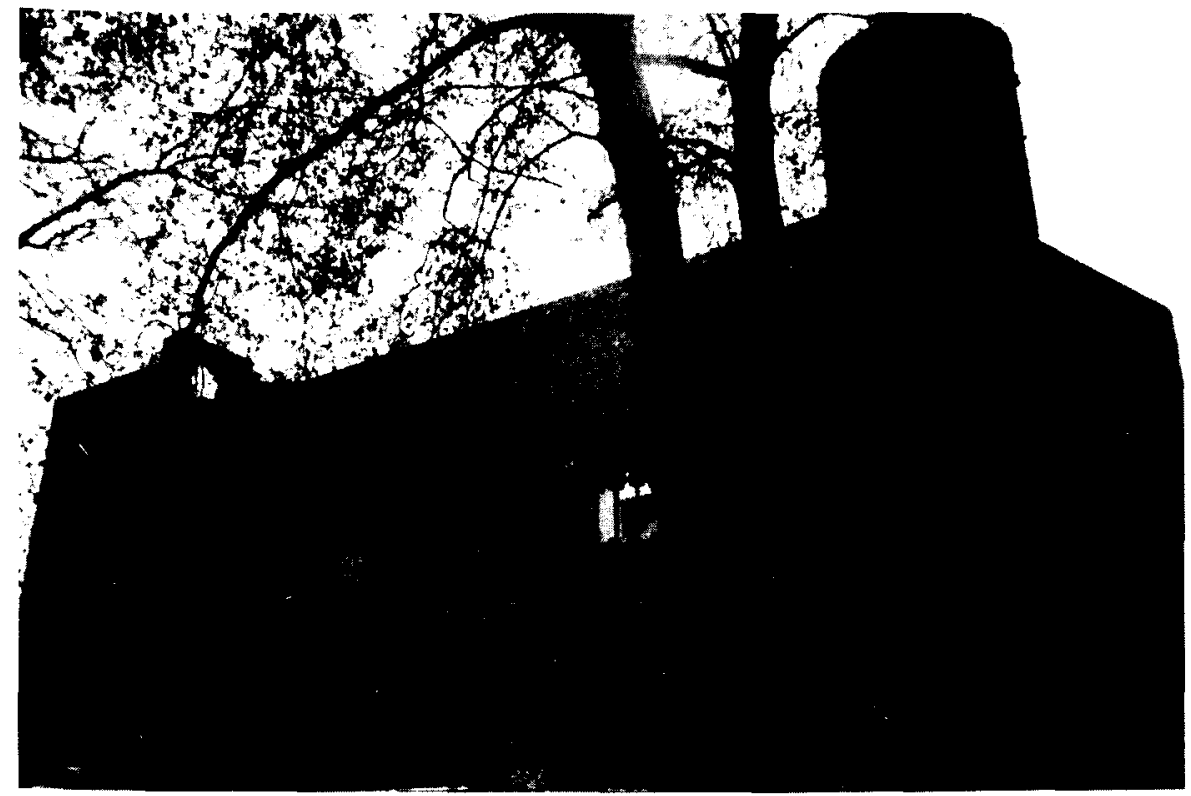

Fig. 10. Crujia Norte al exterior.

se corresponden con su organización interna ni con su sistema de cubiertas.

El alzado de esta torre ofrece además otros pormenores susceptibles de análisis [il. 4, 5]. El grosor de los muros exteriores confirma una vez más su carácter exento. El desnivel entre la base de la torre y el suelo firme, en un estadio inferior, salvando la altura de la roca de asiento, permite suponer la existencia de un acceso elevado al interior de la torre. Su ubicación exacta se desconoce, si bien podría buscarse en alguno de los vanos cegados actualmente, como el del lateral Sur, o el localizado en el lado mayor Este, definido por un arco de medio punto.

Este tipo de acceso insiste en el carácter eminentemente militar de la construcción, donde priman las cualidades defensivas sobre las de habitabilidad.

Son estos vanos impracticables los que permiten conjeturar una distribución interna de la torre en varias estancias superpuestas. A la inferior se accedería por alguno de ellos. A un segundo nivel modificado en época cristiana, correspondería la estancia tripartita a la que ahora se accede desde el patio alto. Más complicado resulta apuntar la posible disposición de un tercer o cuarto cuerpo. 
Estos elementos del alzado analizados están perfectamente documentados desde criterios tipológicos, cronológicos y geográficos.

La uniformidad en altura del recinto - torres menores y lienzos de muralla - es una caracteristica que Brihuega comparte con la arquitectura defensiva del periodo califal (Mérida, El Vacar, Tarifa, o Uclés, un referente muy cercano en el espacio).

La organización en altura de la torre también está documentada en la arquitectura islámica. La distribución interna de Brihuega puede reconstruirse idealmente según modelos como los citados de Cuenca o El Andador, con diversas estancias superpuestas.

Por último, el recurso del acceso en altura al interior de las estructuras defensivas, tiene su origen en épocas pre y altomedievales, para ir desapareciendo progresivamente conforme avanza la Edad Media. Aparece en estructuras militares islámicas de la Marca Media tan emblemáticas como el Castillo de Gormaz.

Es el estudio de materiales y técnicas, planta y alzado, el que permite una reconstrucción hipotética del núcleo original del castillo de Brihuega. Pero este supuesto tiene su fundamento en lo que ha de ser una adscripción formal desde el punto de vista tipológico y cronológico.

La historiografía no se pronuncia en este sentido, excepción hecha de una identificación genérica de la estructura con un hisn o con bury ${ }^{22}$. Bury viene a ser entendido como sinónimo de torre, las estructuras militares más sencillas ${ }^{23}$. Desde luego, el modelo de torres con funciones de refugio y vigilancia llegaría a la Península de la mano del Islam. Presentes en los palacios del desierto, sus verdaderos orígenes se sitúan en los sistemas defensivos de la frontera, del limes romano y bizantino.

No ha de ignorarse, sin embargo, que la torre se complementa con un recinto. Este esquema más complejo se aproxima al concepto de hisn, un castillo propiamente dicho. El hisn se caracteriza por su ubicación elegida en zonas de difícil acceso, por el aprovechamiento de la orografía en el trazado de su recinto y por la disposición de torres en sus ángulos ${ }^{24}$. Estos elementos, aunque en una versión muy sencilla, son los que definen el conjunto de Brihuega.

\footnotetext{
B. Pavón Maldonado, op. cit., pág. 163-164. El autor analiza para la identificación únicamente el aspecto técnico de la estructura y en un punto muy preciso, la torre Suroeste.

L. TORREs Balbas, Ciudades hispano musulmanas, Madrid, 1985, pág. 52.

E. Levi Provencal, "Hispania Musulmana (711.1031) Instituciones, Sociedad, Cultura", Historia de España, dirigida por R Menéndez Pidal, t. V. 2. ${ }^{a}$ ed. Madrid, 1965.
} 
En cualquier caso, el análisis de los caracteres constructivos, el establecimiento de paralelos tipológicos y las inferencias a que dan lugar los datos históricos, permiten enunciar una propuesta de datación y adscripción.

Brihuega, en consecuencia, se comprende en conexión con los hábitats fortificados de los beréberes de Al-Andalus. Los paralelos han apuntado a enclaves situados en la serranía de Cuenca, en el Alto Tajo, y de forma general, en el eje trazado por la Marca Media ${ }^{25}$.

Se trata desde luego de lugares estratégicos, donde las motivaciones topográficas a la hora de elegir la ubicación han sido esenciales. Brihuega viene a compartir con estos núcleos rasgos como la ubicación de la estructura defensiva dominando un valle, con una importante vega. Esto implica el asentamiento de grupos humanos asociados a la fortificación, cuyos sustento y economía quedan así asegurados. El complemento se busca en el monte y el bosque, como recurso cinegético, pero también garante de refugio. Estas características son las buscadas por los pueblos beréberes, y son las que debieron determinar la elección del enclave de Brihuega.

Un último factor común es la orientación al Sur de la ladera donde se asienta la fortificación. Proporcicna un resguardo adicional a la población en una zona de contrastes climatológicos. En este sentido, resultan interesantes algunas fuentes históricas que apuntan la disposición de cuevas habitadas en el corte de la Peña Bermeja sobre el valle ${ }^{26}$. El fenómeno no es extraño a otros enclaves propiedad del arzobispo, como se constata en Yepes o La Guardia, respondiendo a un tipo de hábitat frecuente en el mundo medieval y especialmente en Al-Andalus ${ }^{27}$. Las cuevas generalmente se organizan en las laderas casi verticales donde se ubican las fortificaciones. La población por tanto, no se resguarda en el recinto militar, salvo en ocasiones de peligro y ante eventuales ataques.

Vid. nota 14 y 15. Además E. PuCh, A. Martin, M. A. Negrete, "Hallazgos islámicos en Pajaroncillo (Cuenca)", I Congreso de Arqueologia Medieval Española, Huesca, 1985, t. IV, Zaragoza, 1986, págs. 111-131.

C. Pérez Moreno, La Virgen de la Peña de Brihuega. Madrid, 1884. Sobre el asentamiento de población dependiente del núcleo fortificado, cabe recordar la repoblación que Alfonso $\mathrm{VI}$ llevará cabo ya en el siglo XI, con el establecimiento de pobladores en el Barrio de San Pedro, al Sur del castillo en la bajada hacia el río. El referente, aunque posterior en el tiempo, tal vez pueda apuntar hacia la continuidad del enclave, que coincide asimismo con vestigios documentados para épocas anteriores al dominio islámico, próximos al cauce del Tajuña.

Vid. nuestro trabajo Yepes en la Edad Media. Población, urbanismo, arquitectura. IPIET. Toledo, 1998. 
Brihuega adopta así un modelo de hábitat beréber, abierto, que debió ser tambièn el originario de ciudades como Calatayud, Albarracin, Molina o Cuenca.

La datación para estas estructuras arquitectónicas vinculadas a comunidades beréberes agrícolas, ganaderas y guerreras se ha establecido entre los siglos $\mathrm{I}$ y $\mathrm{x}$. Este acotamiento temporal es perfectamente asumible para el ejemplo briocense. Se sustenta en una cuestión histórico-geográfica. Brihuega no sólo se integra en una línea de frontera, la Marca Media, que le permite relacionarse con núcleos de la importancia de Atienza, Molina o Albarracín. Además está prácticamente integrada en la región ocupada ya desde el siglo vill por población beréber de las tribus Madyuna y Hawwara, coincidente con la zona montañosa comprendida entre las actuales provincias de Teruel, Cuenca, Soria y Guadalajara ${ }^{28}$.

En definitiva, se puede afirmar que el conjunto defensivo analizado constituye el origen del castillo de Brihuega. Los vínculos reiterados sobre las líneas precedentes no hacen sino remitir de forma genérica a la arquitectura islámica peninsular hasta el periodo del Califato. De modo particular, conduce a unas coordenadas temporales y espaciales muy precisas. Éstas son el ámbito del Alto Tajo, un periodo que discurre entre los siglos I y y y un modo de construir muy característico de la primera arquitectura hispanomusulmana, el llevado a cabo por los contingentes beréberes que se adentraron con la invasión de la Península.

28 La adscripción general permite no desestimai una posible relación con la hipótesis de BosCh VILA, relación que ya S. MARTinez LILLO, op. cit., pág. 150, establece para el foco de fortificaciones del entorno de Talavera. Evoca también un posible núcleo beréber en Ercávica (Cuenca) y hawwara en Cañete, confirmando la presencia de estas tribus en zonas montañosas o de la linea frontera. 